\title{
ESTRATEGIA DE INTERNACIONALIZACIÓN DEL EJÉrCito de Liberación NaCional (ELN) Y SEGURIDAD FRONTERIZA
}

María Camila Luna Beltrán*

\section{Resumen}

¿Cuál es el alcance que puede llegar a tener una estrategia de internacionalización diseñada, no desde un Estado, sino desde un grupo subversivo como el ELN? Para responder a esta pregunta se revisaron conceptos referentes a la internacionalización, y se analizaron las líneas del ELN sobre esta, ancladas en su origen e inicios; la estrategia de internacionalización en medio de las negociaciones de paz, y la regionalización por el repliegue del ELN hacia zonas fronterizas. Además, se estudió el impacto de esta estrategia en la dinámica general del conflicto colombiano y la seguridad fronteriza. Finalmente, se evalúa la correlación de fuerzas e incentivos para la actual negociación de paz Gobierno-ELN.

Palabras clave: internacionalización, regionalización, estrategia, conflicto, ELN.

\section{INTERNATIONALIZATION STRATEGY OF THE NATIONAL LIBERATION ARMY AND BORDER SECURITY}

\begin{abstract}
What is the scope of an internationalization strategy implemented, not by a state, but by a subversive actor such as the ELN? To answer this question the concepts concerning the internationalization of armed conflicts are reviewed; later, the lines of internationalization of the ELN anchored in their origin and early years are analyzed. Next, the strategy of internationalization in the middle of peace negotiations is studied, as well as the regionalization by the ELN's withdrawal to border zones. Finally, the impact of the internationalization strategy on the general dynamics of the Colombian conflict and the frontier's security is considered,
\end{abstract}

* Máster en Asuntos Internacionales. Profesional Especializado - Cooperación - Secretaría Distrital de Salud, Bogotá (Colombia). [camilalunab@gmail.com].

Recibido: 6 de marzo de 2018 / Modificado: 31 de julio de 2018 / Aceptado: 1 de agosto de 2018.

Para citar este artículo

Luna Beltrán, M. C. (2018). Estrategia de internacionalización del Ejército de Liberación Nacional (ELN) y seguridad fronteriza. OPERA, 23, 139-162.

DOI: https://doi.org/10.18601/16578651.n23.09 
evaluating the correlation of forces and incentives present in the current Government-ELN peace negotiation.

Key words: Internationalization, regionalization, strategies, conflict, ELN.

\section{INTRODUCCIÓN}

En el estudio de la internacionalización de los conflictos armados (en adelante internacionalización), existe una tendencia a reconocer al Estado como único actor válido para iniciar este proceso. Sin embargo, esta investigación considera que el ELN ha desarrollado, en su calidad de actor subversivo, a partir de la toma racional y calculada de decisiones, su propia estrategia de al respecto. Ahora bien, ¿`cuál es el alcance que puede llegar a tener una estrategia de internacionalización diseñada, no desde un Estado, sino desde un grupo subversivo como el ELN, entendiendo el alcance tanto en términos de su concepción como de las posibles consecuencias de su implementación?

La investigación parte de la internacionalización definida como "el proceso mediante el cual se toma una decisión explícita y consciente: la decisión de implicar a actores internacionales en cualquier fase -de hostilidad o negociación-de un conflicto interno" (Borda, 2012). En la literatura académica ha predominado la visión de la internacionalización como consecuencia de situaciones estructurales que conducen a que actores internacionales intervengan, casi de manera impuesta o inevitable, en el desarrollo del conflicto interno de un país (Hoffman y Forbes, 1993).
Respecto a los elementos que explican la internacionalización, estos pueden ser internacionales y nacionales. Sobre los primeros existen dos corrientes: teorías oportunistas, referentes al beneficio que recibe un Estado por la debilidad del otro, y teorías intervencionistas, referentes al interés de otro Estado en que un grupo insurgente obtenga la victoria. En cuanto a los factores nacionales, se mencionan identidades de los actores e intereses nacionales, que responden a procesos racionales de toma de decisiones, diseño de estrategias y consecución de objetivos. Según los objetivos, se habla de internacionalización politica (cuando se busca obtener legitimidad) o de internacionalización militar (cuando se busca apoyo militar para continuar la guerra) (Borda, 2012).

Así, plantea como hipótesis que el ELN desplegó una estrategia de internacionalización que abrió la puerta a que diferentes actores internacionales se involucraran, directa o indirectamente, en el conflicto colombiano, lo cual cambió su configuración al jugar también un papel fundamental en el crecimiento, descenso y repliegue de dicha guerrilla, que desembocó en una regionalización del conflicto por su actividad en zonas de frontera.

Para estudiar dicha hipótesis se implementó una metodología mixta de investigación. En primer lugar, se revisaron textos, publicaciones e informes originales del ELN, así como informes de prensa, comparando los lineamientos políticos plasmados por esta guerrilla en distintos documentos, con la actuación armada e internacional del ELN. Lo anterior se complementó con una evaluación 
de fuentes secundarias a partir de las cuales se establecieron las líneas de internacionalización del ELN y las transformaciones de esta estrategia en medio de las negociaciones de paz.

Posteriormente, se realizaron cuatro entrevistas semiestructuradas a los profesores Jaime Zuluaga, Humberto Vergara, Luis Eduardo Celis y al periodista Víctor de Currea-Lugo, expertos en temas referentes al ELN. El ejercicio, más allá de la información recolectada, resultó ilustrativo en cuanto a las dificultades todavía generalizadas a la hora de estudiar a este grupo: las opiniones de los académicos consultados respecto a esta guerrilla resultaron diametralmente diferentes en algunos puntos clave, y evidenciaron lo mucho que se desconoce todavía de la historia del ELN, vacío que no ha sido resuelto tampoco desde la misma organización; además, no fue posible contactar otros expertos. En este sentido, es importante aclarar que los apartados de las entrevistas que se incluyen en este artículo son las opiniones de los entrevistados, por lo que deben ser evaluadas con discernimiento y en un contexto académico e histórico.

De otro lado, se adelantó la revisión de bases de datos obtenidas del Observatorio de Memoria y Conflicto ${ }^{1}$ (OMC), a partir de las cuales se realizó un análisis temporal de datos cuantitativos de las acciones del ELN en el conflicto colombiano, buscando posibles relaciones entre la implementación de su estrategia de internacionalización y su capacidad bélica. El procesamiento de información estadística y nacional permitió caracterizar cambios en la iniciativa armada del ELN, revisar su alcance frente a la actividad militar del Estado y comparar la iniciativa de esta guerrilla frente a la de otros grupos armados.

El análisis de estos insumos resulta pertinente porque el conflicto colombiano se encuentra hoy en uno de sus procesos de transformación más importantes: las Fuerzas Armadas Revolucionarias de Colombia (FARC) y el Gobierno nacional finalmente firmaron un acuerdo de paz que condujo a la desmovilización de este grupo, y abrió la puerta a la reconfiguración del conflicto. De hecho, ahora que han iniciado los diálogos de paz con el ELN, considerar los alcances de su estrategia de internacionalización, y en qué medida tuvo consecuencias para el conflicto armado colombiano y para la búsqueda de la paz, resulta necesario.

\section{INTERNACIONALIZACIÓN DESDE EL ORIGEN}

El 4 de julio de 1964, con la marcha guerrillera hacia Simacota, nace oficialmente el ELN, producto de la confluencia de factores nacionales e internacionales como los remanentes del movimiento gaitanista y de la guerrilla liberal de Rafael Rangel Gómez en Santander,

\footnotetext{
$1 \quad$ "El omc documenta los casos que conoce a partir de diferentes fuentes de información que logra acopiar y los clasifica a partir de los criterios conceptuales y operativos definidos para ese fin. Asimismo, se debe tener en cuenta que los casos que documenta el Observatorio están en constante proceso de actualización, razón por la cual los datos presentados pueden registrar cambios en futuros cortes de información. Por ello, solicitamos amablemente tener en cuenta la fecha de corte que aparece en cada tabulado" (Observatorio de Memoria y Conflicto, 2017).
} 
la atmósfera creada por La Violencia, Rojas Pinilla, el Frente Nacional y, finalmente, la Revolución Cubana, que sería determinante para imprimir de sentido, decisión y orientación la creación de este movimiento (Medina, 2012). Este enraizamiento en la Revolución Cubana sería punto de partida de su estrategia de internacionalización.

\section{Cuba y la "revolución continental"}

En 1962, un grupo de estudiantes viajó a Cuba con becas del gobierno Castro; algunos de ellos terminaron adiestrándose en lucha guerrillera y, finalmente, siete regresaron a Colombia para conformar la Brigada Proliberación José Antonio Galán. Fabio Vásquez y Víctor Medina, sus principales líderes, empezaron a sentar las bases del ELN; en consecuencia, los principios de su proyecto revolucionario respondieron, significativamente, a la Revolución Cubana. La isla seguiría teniendo un importante rol en las decisiones del grupo guerrillero, especialmente durante su primera década de existencia: a finales de 1974, nuevas generaciones de combatientes seguían entrenándose en Cuba y desde allí, en 1975, Vásquez asumió la representación internacional de la organización y se proyectó como dirigente remoto de la misma (Medina, 2012).

Dicha necesidad de asumir la representación internacional del grupo ciertamente respondía a que, como descendiente del proceso cubano, el ELN hacía parte de una dinámica internacional de atomización del movimien- to revolucionario (movimiento comunista internacional) a escala mundial. Como la Revolución Cubana tuvo que enfrentarse con Estados Unidos al poco tiempo de su triunfo, Cuba terminó abriéndose a una dimensión internacional que estaría representada en el proyecto de la "revolución continental"2; en este contexto nace el ELN (Zuluaga, 2017).

Aunque el ELN enmarcaba su lucha en el ámbito internacional, sus objetivos revolucionarios eran netamente nacionales. Sin embargo, sectores sociales que se vincularon al ELN, como sindicalistas o líderes universitarios, contaban con asociaciones internacionales, que fortalecían la visión de una dinámica internacional antiimperialista: la revolución nacional no tenía perspectiva sin la dimensión internacional, y el Estado colombiano adquiría el rostro de un "agente del imperialismo" (Zuluaga, 2017).

De otro lado, la visión continental y global de la lucha antiimperialista condujo a que, con Cuba como enlace, y en reuniones de la Organización Latinoamericana de Solidaridad, se articularan diferentes movimientos de Asia, África y, especialmente, América Latina, para definir estrategias conjuntas de lucha armada contra el imperialismo; no obstante, resulta difícil determinar qué alcance tuvieron estas alianzas puesto que no existen mayores publicaciones que las referencien (Zuluaga, 2017).

En el marco de la lucha continental, la Revolución Sandinista nicaragüense influenció significativamente al ELN, pues algunos militantes estuvieron bajo el mando del Frente

\footnotetext{
2 Para ahondar en los motivos por los cuales Cuba decide apoyar las guerrillas latinoamericanas, incluido el ELN, se sugiere consultar a Allison (1971).
} 
Sandinista de Liberación Nacional y, siguiendo este referente, el ELN determinó necesario sostener el carácter violento de la revolución, la labor diplomática internacional de unidad y solidaridad revolucionaria y la clandestinidad de las distintas formas de lucha (AH-ELN, 2012). Igualmente, el encuentro del ELN con las experiencias revolucionarias de Nicaragua, El Salvador y Guatemala lo condujo, a inicios de los años ochenta, a rediseñar su estrategia revolucionara migrando del concepto cubano de la guerra de guerrillas hacia la guerra popular prolongada (Medina, 2015).

Una vez establecida esta nueva estrategia revolucionaria, que enfatizaba la internacionalización de la lucha armada (la unión de fuerzas de izquierda por una revolución continental), el eLn diseñó la Cartilla de trabajo internacio$n a l^{3}$ (1989). Según este documento, el Colectivo de Trabajo Internacional se instalaría en Cuba para obtener, a través de la lucha política y diplomática, solidaridad y reconocimiento internacional para el proyecto revolucionario, posibilitando alianzas con otros Estados y fuerzas políticas (Semana, 2000).

El Colectivo priorizó el establecimiento de contactos políticos con movimientos subversivos y políticos afines y geográficamente próximos como el salvadoreño Frente Farabundo Martí para la Liberación Nacional, y la Unidad Revolucionaria Nacional Guatemalteca. Posteriormente, el ELN buscó ampliar las alianzas suramericanas, acercándose al Túpac Amaru (Perú) y al Movimiento Revolucionario Patria Libre (Paraguay). Adicionalmente, se profundizó el plan estratégico con los grupos políticos de izquierda suramericanos (Semana, 2000).

Teniendo en cuenta que con una estrategia de internacionalización política el Estado busca legitimidad y apoyo internacional a favor de su derecho a gobernar, y los grupos insurgentes buscan legitimidad y apoyo internacional para su derecho de lucha contra un Estado ilegítimo y represor (Borda, 2012), se entiende que el escenario internacional sea un campo de batalla en el que se despliegan medios discursivos para deslegitimar el proyecto político por el que lucha el contrario y legitimar el propio; así, según lo propuesto por Clausewitz, y en caso de tener un despliegue exitoso de la estrategia de internacionalización, se debilita la voluntad y, por tanto, la fuerza del enemigo, modificando la realidad y transformando el escenario de la confrontación.

Si bien la legitimidad interna y la internacional son diferentes, y generalmente no son complementarias, "la legitimidad internacional podría considerase como un sustituto temporal ante la ausencia de legitimidad interna" (Borda, 2012). De cualquier manera, lo revisado evidencia que el ELN, por su origen enraizado en la Revolución Cubana, tenía una inherente dimensión internacional, al moverse bajo la dinámica de alianzas de la "revolución continental".

3 A pesar de múltiples indagaciones y búsquedas, esta investigación no pudo conocer una copia del documento. No obstante, algunos de los entrevistados (Zuluaga, Vergara y Celis) afirmaron que la existencia del mismo es muy probable y, de hecho, Celis afirmó que el documento sí existe, ya que en 1983, con la superación de la crisis interna, el ELN empieza a reconstruir sus relaciones internacionales a través de alias Evelio y alias Jacinto, coyuntura en la cual se crea el Equipo de Trabajo Internacional, regido por el documento en cuestión (Celis, 2017). 


\section{INTERNACIONALIZACIÓN RELIGIOSA}

Para Zuluaga (2017), otra vía de temprana internacionalización del ELN fue el cristianismo. Ya había en este grupo una fuerte concepción cristiana, pero la corta vinculación de Camilo Torres fue fundamental para consolidarla. Ideológicamente, la presencia del cristianismo se asocia después a la teología de la liberación, concepto que se resume en la frase de Torres: el deber de todo cristiano es ser revolucionario (Medina, 2012).

Efectivamente, el paso de Torres por el grupo motivó a tres curas españoles, José Antonio Jiménez, Domingo Laín y Manuel Pérez, a vincularse al ELN. En 1969, Laín asumió como segundo al mando y, en 1978, Pérez fue elegido como comandante del ELN hasta el año de su muerte (1998) (Aguilera, 2006). Lo anterior es relevante porque

... ninguna otra guerrilla colombiana tuvo un comandante español que, además, era cura. Eso implica, de hecho, una apertura hacia el resto del mundo que no tienen las otras guerrillas, porque esto es más que el discurso ideológico, y es la presencia real y efectiva de lo que se puede entender como la solidaridad internacional (Zuluaga, 2017).

Aguilera (2006) sostiene que, hasta comienzos de la década de los noventa, decenas de religiosos mantenían su colaboración externa con el ELN. Adicionalmente, explica que heredaron algunas de las organizaciones creadas por seguidores católicos, y que los religiosos introdujeron una nueva metodología al trabajar directamente con las comunidades, para obtener beneficios colectivos.
Sin embargo, aunque las comunidades religiosas han logrado presencia en áreas de conflicto a las que ninguna organización no religiosa ha podido llegar, y se han convertido en vehículos indispensables de cooperación internacional para la paz (Henao, 2014), hay quienes afirman que la llegada de guerrilleros de otras latitudes al ELN es algo meramente anecdótico, por lo cual plantear aquí un lazo de internacionalización es difícil (Currea-Lugo, 2017); el debate, entonces, queda abierto.

\section{Internacionalización e hidrocarburos: Alemania y los Maüss}

En el marco de la Reunión Nacional Héroes y Mártires de Anorí (1973), el ELN introduce una línea discursiva novedosa: una apertura de la visión de las dimensiones internacionales implicadas en el conflicto, entendida ahora bajo la cuestión de los hidrocarburos nacionales y la explotación de los mismos por compañías extranjeras multinacionales $(\mathrm{Zu}-$ luaga, 2017).

En consecuencia, su estrategia pasa a ser la profundización de la crisis del régimen a través de una ofensiva táctica en territorios de interés estratégico, como el sector energético (Medina, 2012). Así, la explotación minera impulsó al ELN hacia una economía predatoria, dependiente del cobro de extorsión a las empresas petroleras, bajo amenaza de voladuras a los oleoductos (Palacios, 2012). Lo anterior generaría una importante relación entre esta guerrilla y Alemania.

El área tradicional e histórica de despliegue de los frentes del ELN coincidió con el recorrido del oleoducto entre Caño Limón 
(Arauca) y Coveñas (Sucre) (Echandía, 2013). La Mannessman, multinacional alemana, fue contratada para construir dicho oleoducto; en 1984, el elN secuestró a cuatro de sus ingenieros, generando los primeros contactos entre esta guerrilla y los Maüss, una pareja de espías del Gobierno alemán, enviados para negociar el rescate y algún tipo de acuerdo que le permitiera a la multinacional ejecutar la construcción del oleoducto (Palacios, 2012).

Se calcula que el valor del rescate giró en torno a ocho millones de dólares, cuatro de los cuales recibió directamente el ELN, dinero que le permitiría reactivar su lucha insurgente, agonizante por pugnas dentro del grupo. La mitad restante se destinó a un programa social que Palacios (1999) llamó "el modelo de la caja de galletas", pues en este colaboraban la guerrilla, la Iglesia y los alcaldes. Los vínculos fueron fortaleciéndose y en 1988 una delegación del ELN viajó a Alemania para visitar el Parlamento Europeo, después de una nueva negociación por el secuestro de 12 ciudadanos europeos, acción que justificaban bajo la campaña "Vida y soberanía Manuel Gustavo Chacón”, que propendía por la nacionalización de la explotación petrolera (Semana, 1999).

\section{INTERNACIONALIZACIÓN DESPUÉS DEL TERCER CONGRESO}

El ELN introdujo cambios en su discurso con el Tercer Congreso (1996): la gestión diplomática cobró vigor dentro de la estrategia de internacionalización y se decidió abrir espacio para la salida negociada del conflicto, argumentando que un buen proceso sirve para recuperar credibilidad y legitimidad frente a la comunidad nacional e internacional (Medina, 2012). Asimismo, fue el primero en reclamar presencia internacional para la negociación lo que, para Zuluaga (2017), no respondía solo a la búsqueda de garantías sino, también, a la concepción de que el conflicto colombiano hacía parte de una dinámica internacional.

La dimensión humanitaria cobró especial relevancia, pues se convirtió en el medio a través del cual, desde finales de la década de los ochenta, el eln se ha acercado discursivamente a algunos gobiernos y comunidades religiosas. Así, ha manejado un claro discurso en defensa de los derechos humanos, argumentando que son la base de la justicia social y que su violación es la causa de la violencia en el país; de esta manera, se convirtió en el primer grupo que planteó la necesidad de aplicar el Protocolo II adicional a los Convenios de Ginebra, incluso antes de que este fuera ratificado por el Gobierno (Schlenker y Iturralde, 2006).

No obstante, es importante recordar que, en Colombia, todos los actores del conflicto han usado profusamente el discurso de respeto a los derechos humanos, a pesar de su reiterada vulneración. Ello porque la presión ejercida por las ONG, los Estados que prestan ayuda económica y militar, y las organizaciones de Estados, ha generado que la responsabilidad de respetar y proteger los derechos humanos, usualmente atribuida exclusivamente al Estado, se extienda a los grupos al margen de la ley. Sumado a esto, los grupos armados han tenido la necesidad de adquirir un estatus de beligerancia que les permita negociar con el Gobierno y obtener el apoyo de otros Estados y organizaciones como interlocutores políticos legítimos (Schlenker y Iturralde, 2006). 
Los diálogos de paz entre el ELN y los Gobiernos de turno evidenciaron que esta guerrilla decidía, de manera estratégica, internacionalizar el conflicto al otorgar a la comunidad internacional, no solo el rol de garante y facilitador sino, también, el de legitimador de la organización, pues era en quienes buscaba el reconocimiento de su estatus de beligerancia y que se ejerciera la presión necesaria para que el Gobierno de turno se sentara a la mesa de negociación.

\section{INTERNACIONALIZACIÓN HACIA VENEZUELA}

La primera negociación de paz con el ELN, como parte de la Coordinadora Guerrillera Simón Bolívar, ocurrió en el gobierno Gaviria (1990-1994). Los diálogos se llevaron a cabo en medio del conflicto, en Caracas y Tlaxcala, pues afirmaban que trabajar fuera les permitía negociar más tranquilamente. Según Vergara (2017) la mediación venezolana fue fundamental en el proceso y permitió, con la elección presidencial de Chávez, un entronque cubano-venezolano. Finalmente, el ELN terminaría convirtiéndose en una ficha clave para las relaciones entre Colombia y Venezuela.

No obstante, Vargas afirma que el ELN hizo parte de la negociación

... más jalonado por las Farc que por una real convicción de que la hora de la paz hubiera llegado. Por ello, sus delegados jugaron más un rol de "freno" a posibles acuerdos, y de hecho las conversaciones de Caracas se suspendieron por un atentado que hizo el ELN contra la caravana del presidente del Senado de la época (Vargas, 2014).
Más allá del resultado, la negociación reforzó el vínculo entre el ELN y Venezuela que, para Celis (2017), ocurre en cuatro niveles: primero, una relación política con la presidencia venezolana, ya que dicho Gobierno le apunta a una salida negociada del conflicto colombiano; segundo, una relación ideológica con la izquierda venezolana que data de los primeros años de alianzas entre las izquierdas latinoamericanas en torno a la "revolución continental"; una tercera relación de negocios; y una cuarta relación territorial, por la presencia del ELN en Venezuela.

\section{Gobierno Samper: el peso de la relación con Alemania}

Posteriormente, el ELN intentaría negociar con el gobierno Samper (1994-1998), solicitando directamente la incorporación del derecho internacional humanitario (DIH) y la mediación de la comunidad internacional (Movimiento de Presos Políticos "Camilo Torres Restrepo”, 2016). Con esta negociación se hizo evidente la fuerza y profundidad que había adquirido la relación entre esta guerrilla y Alemania.

Era de gran importancia para el Gobierno alemán que se lograra la paz con el grupo insurgente. En 1995, las interacciones entre los Maüss y el ELN se reanudaron; los Maüss regresaron a Alemania con un borrador de un documento sobre la paz (Semana, 1999), y una nueva delegación de guerrilleros viajó a Europa en 1996. El proceso de paz fue suspendido en el mismo año debido al secuestro de la alemana Brigitte Schönne, por quien solicitaron un rescate de 1,5 millones de dólares para 
su liberación. En privado, el Gobierno alemán negoció con los insurgentes y, posteriormente, decidió apoyarlos en su búsqueda de una salida política del conflicto (Semana, 1999).

La relación entre el Gobierno alemán y el eLN adquirió tal importancia que en julio de 1998 el canciller alemán Helmut Kohl, los Maüss y el Episcopado alemán impulsaron el Acuerdo de Puertas del Cielo, firmado el 15 de julio de 1998, en Mainz (Alemania), donde se acordaba dar inicio al Proceso de Paz con el ELN, con la mediación de la Conferencia Episcopal alemana y colombiana (Medina, 2012).

Sin embargo, en abril de 1999 las negociaciones de paz se suspendieron y el estatus político del ELN fue revocado por el secuestro de un avión de Avianca con 46 pasajeros a bordo y de 63 personas de la congregación de la iglesia La María en Cali. Ante el crítico escenario, el congresista Schmidbauer, los Maüss y el principal dirigente del eln, Nicolás Rodríguez Bautista alias Gabino, se reunieron en Alemania para convencer a la comunidad internacional de que los secuestros respondían a la necesidad política de ejercer presión para negociar con el Gobierno colombiano y, además, solicitar la participación de Alemania en el proceso de paz como requisito para la liberación de los secuestrados. Finalmente, se acordó la participación en las negociaciones de tres legisladores alemanes (Borda, 2012).

Adicionalmente, la guerrilla se aproximó a la comunidad religiosa de San Egidio (Italia) y al Gobierno español. En consecuencia, se estableció una mesa de diálogo en Madrid y, en febrero de 1998, se redactó el Preacuerdo de Viana como la primera expresión formal del compromiso del elN con un acuerdo humanitario en el marco del DiH. Sin embargo, el preacuerdo nunca se ratificó dada la muerte del dirigente Manuel Pérez en este mismo mes (Zuluaga, 2017).

Lo ocurrido en 1999 demostró cómo el ELN aprovechó los contactos obtenidos con el secuestro de los ingenieros europeos para desplegar una estrategia de internacionalización política cuyo principal objetivo era obtener, de los gobiernos extranjeros, el respaldo del que carecía a nivel nacional.

\section{Gobierno Pastrana: erosión de la legitimidad}

Con el gobierno Pastrana (1998-2002) se reinician los suspendidos diálogos de paz gracias a la liberación de los secuestrados del ELN y a la búsqueda por parte del Gobierno de despejar una zona para negociar. Sin embargo, y contrario a lo que se esperaba, dado que los municipios seleccionados ${ }^{4}$ tenían una presencia de larga data del eln, la Asociación Civil para la Paz, principalmente, desató una oposición radical a la iniciativa.

Lo anterior se explicaba porque los paramilitares, a través de intimidaciones y de los recursos derivados del narcotráfico, se consolidaron como poder socioeconómico en las regiones de antigua influencia del ELN (Valencia, 2014). Ello generó cambios en la vida política y electoral de las regiones, y minó los

4 Los municipios del Magdalena Medio: Santa Rosa, Simití, San Pablo y Morales (González, 2015). 
acuerdos que permitían la convivencia entre la guerrilla y la clase política local antes de 1996 (Gutiérrez, 2004).

Sin embargo, las conversaciones continuaron y contaron, desde el 2000, con la colaboración del concertado Grupo de Países Amigos (Francia, España, Noruega, Suiza y Cuba). El 12 de marzo de 2002, en La Habana, el Gobierno y el eLN firmaron una declaración de intención para avanzar hacia la tregua, pero el 31 de mayo de 2002 el Gobierno suspendió definitivamente los diálogos argumentando falta de voluntad por parte del ELN quien, a su vez, afirmó que el presidente había priorizado la tregua sobre un acuerdo de humanización de la guerra (Ávila y Ávila, 2016).

\section{Gobiernos Uribe y Santos: de negociación fallida a negociación incierta}

El gobierno Uribe (2002-2010) buscó sentar las bases para negociar con el ELN. En 2003 se reactivó el Grupo de Países Amigos con la baja de Francia y España, a quienes la guerrilla rechazó por haber sido incluidos en la lista de organizaciones terroristas de la Unión Europea. En 2004 solicitan la mediación de México, la cual dura hasta abril de 2005 debido a tensiones entre el presidente Fox y Cuba. Después de ocho diálogos exploratorios el proceso se suspende y se reanuda en agosto de 2007 bajo el auspicio de Venezuela y la exsenadora Piedad Córdoba (Ávila y Ávila, 2016).

Más tarde se evidenció que el ELN había aprovechado la coyuntura del proceso de paz para desplegar una estrategia de internacionalización de mayor envergadura: aprovechó el contexto de las conversaciones para fortalecer su relación con los países vecinos, especialmente con Venezuela, a cuyo presidente dirigieron una carta, en 2008, solicitando que se les reconociera como fuerza beligerante (Borda, 2012). Cuando Chávez otorga el reconocimiento de beligerancia al eLN, Uribe lo desautoriza como mediador en la liberación de secuestrados y las relaciones diplomáticas entre ambos mandatarios se rompen definitivamente (Ávila y Ávila, 2016).

Desde 2014, la guerrilla del elN estuvo en negociaciones con el gobierno Santos (20102018). La etapa de exploración de los diálogos de paz se realizó en Venezuela, Brasil y Ecuador, y en marzo de 2016 se dieron a conocer los seis puntos de la agenda acordada: 1) participación de la sociedad en la construcción de paz, 2) democracia para la paz, 3) transformaciones para la paz, 4) víctimas, 5) fin del conflicto armado y 6) implementación de los acuerdos. Casi un año después, en febrero de 2017, se instaló la mesa de negociación en Quito, con Cuba y Noruega como garantes del proceso.

Según lo expresado por Currea-Lugo (2017), para el elv la paz no es posible sin el acompañamiento de la comunidad internacional, dada la desconfianza que sienten respecto al cumplimiento del Gobierno, lo que hace que solo sea posible la veeduría y garantía de la comunidad internacional, especialmente de aquellos actores en quienes tienen un mínimo grado de confianza como Cuba, Venezuela, Ecuador, Suiza, Noruega, la Iglesia católica, las once embajadas que acompañaron el proceso, Naciones Unidas, el Comité Internacional de la Cruz Roja, voceros y organizaciones de las comunidades locales y organizaciones de derechos humanos. 
Adicionalmente, afirma Currea-Lugo (2017) que existe una clara estrategia de internacionalización del ELN, entendida en términos de apoyos para la construcción de paz; en el marco de la misma, continúa, esta guerrilla cuenta hoy con el apoyo de México, Venezuela, Ecuador y del gobierno de Raúl Castro que, con el permiso del Gobierno colombiano, ha realizado cumbres entre dirigentes del ELN y de las FARC.

Entonces, los diálogos de paz evidenciaron que el ELN ha sido una guerrilla propensa, desde sus orígenes, a entablar relaciones con actores internacionales. Adicionalmente, desde el Tercer Congreso pretendió afianzar dichas relaciones para obtener reconocimiento político por parte de Gobiernos y organizaciones de derechos humanos de la Unión Europea.

\section{INTERNACIONALIZACIÓN HOY: FRONTERAS Y NARCOTRÁFICO}

La creciente presencia del ELN en las zonas de frontera ha generado otra forma de internacionalización: la regionalización, entendida como expansión o derrame del conflicto colombiano hacia los países vecinos, y como fenómeno limitado que depende de los actores involucrados en la confrontación, de la interacción de los diferentes sectores de esos países vecinos con visiones del conflicto colombiano y de sus vínculos transnacionales (Ramírez, 2006).

Si bien el ELN ha mantenido una presencia histórica y tradicional en los municipios de Boyacá, Casanare, Arauca y Catatumbo, estos territorios han ganado valor estratégico por el acceso a la frontera con Venezuela. En general, las fronteras siempre han sido útiles porque garantizan la financiación a los grupos armados a través de economías de guerra (extorsiones, secuestros, contrabando, cultivos ilícitos, entre otras) y de mercados ilegales transnacionales, cuyos recursos se traducen en capacidad bélica. También se considera que estas han asegurado la permanencia de los actores en la confrontación gracias al establecimiento de zonas de refugio, descanso y tráfico (corredores), lo que ha facilitado la expansión de la presencia guerrillera (Cabrera, 2012).

Los análisis geográficos de la presencia del ELN en el territorio nacional demuestran que, aun cuando esta guerrilla no tiene la capacidad de realizar operaciones de gran magnitud, mantiene una actividad armada importante en los departamentos limítrofes; así, más de la mitad de los municipios en los que mantiene presencia activa se localizan en zonas de colonización interna y de frontera (Echandía, 2013). Al respecto, es importante recordar que "los grupos irregulares están en la capacidad de instrumentalizar el espacio, en función de consideraciones militares, directamente asociadas con la dinámica bélica" (Cabrera, 2012), por lo cual, esta relocalización de las estructuras armadas debe ser entendida como una respuesta estratégica ante la situación de ofensiva militar en su contra. Así, el posicionamiento del ELN en zonas de frontera ha respondido a una estrategia de repliegue que le ha otorgado un margen de maniobra para posibilitarle evadir la acción de la fuerza pública y de los paramilitares, garantizarle su financiamiento, y el establecimiento de áreas de refugio y contacto con el exterior (Echandía, 2015). 
Específicamente, la instrumentalización de la frontera con objetivos de financiación y control territorial está relacionada con el narcotráfico. Inicialmente, esta guerrilla había asumido un deslinde categórico con las mafias del narcotráfico, con el fin de tomar distancia de la política antidroga de Estados Unidos (Medina, 2012). No obstante, la entrada en escena de las Autodefensas Unidas de Colombia (AUC), sumada a los conflictos locales y a la confrontación con la Fuerza Pública, le generaron un impacto militar considerable que lo condujo a acogerse a nuevas formas de financiación involucradas con el narcotráfico. Específicamente, en departamentos como Arauca, Nariño y Cauca, implementaron tareas de vigilancia del comercio y la distribución de la coca, controlando pasos fronterizos (Corporación Nuevo Arcoiris, 2013).

$\mathrm{Al}$ respecto, Echandía (2015) afirma que la rivalidad entre las FARC y el ELN en el corredor que va de la vereda Botalón hasta Puerto Lleras, en la frontera con Venezuela, se explica en la pugna por el control de un territorio propicio para sacar cocaína desde Colombia hacia Venezuela y que, "entrevistas en la zona permitieron establecer que el frente Domingo Laín estuvo involucrado en este eslabón del negocio hasta el último pico de los cultivos registrado en 2007, con lo cual se esclarece el trasfondo de la confrontación entre las guerrillas" (Echandía, 2015).

En este sentido, resulta fundamental entender que los cultivos de coca, más que objeto de la disputa, son un mecanismo para avanzar en la confrontación por el control territorial. Ello ocurre porque la coca copa la economía local, redefiniendo como mercantil la relación entre los grupos armados y la población local; "quien controla la coca es quien pone las reglas de la producción y el mercado, los demás quedan al margen” (FIP, 2005).

El negocio de las drogas requiere abrir corredores clandestinos desde los puntos de cultivo y procesamiento hacia los dos mares y las fronteras internacionales, con el objetivo de contrabandear precursores químicos, armas, dinero y cocaína o heroína (Palacios, 2012). Así, el narcotráfico, ligado al conflicto armado, ha tenido un impacto directo sobre las relaciones internacionales del país y, particularmente, en las relaciones con los países vecinos, lo que ha generado la regionalización del conflicto (Ramírez, 2006).

Actualmente, con el acuerdo de paz de las FARC, la territorialidad del conflicto cobra mayor importancia; las estructuras de dicha guerrilla han dejado libre el $98 \%$ del territorio donde operaron durante décadas, y como en 49 de estos municipios el ELN ya tenía presencia, ha aprovechado la salida de las FARC para consolidarse como actor dominante y expandirse hacia 12 municipios más en los cuales no tenía presencia (Fundación Paz y Reconciliación, 2017). Adicionalmente, todo apunta a que, desde 2015, varios integrantes de las FARC están migrando a las filas del ELN (Álvarez et al., 2017).

Este fortalecimiento territorial pos-FARC le posibilita también al ELN un mayor acceso a las rentas del narcotráfico, lo que le concedería los medios para prolongar el conflicto. No debe olvidarse que, a pesar de la vertiginosa reduc- 
ción del grupo previa a este nuevo escenario ${ }^{5}$, el Comando Central del elN se mantiene intacto desde 1998 gracias a que, desde hace más de diez ańos, sus principales líderes decidieron refugiarse fuera del país, a fin de evitar golpes contundentes como los que recibieron las FARC (Echandía C., 2013).

En ańos recientes, entonces, la internacionalización del eLN ha tenido un carácter regional enmarcado, en una medida importante aunque no absoluta, por estrategias de financiación relacionadas con el narcotráfico, y por estrategias relacionadas con la instrumentalización de las fronteras como zonas de refugio.

\section{IMPACTO DE LA INTERNACIONALIZACIÓN EN LA DINÁMICA DEL CONFLICTO Y LA SEGURIDAD FRONTERIZA}

$\mathrm{Al}$ periodizar el histórico de acciones llevadas a cabo por iniciativa del ELN, es posible revisar el posible impacto de la estrategia de internacionalización sobre la dinámica del conflicto colombiano y, en particular, sobre las condiciones de seguridad fronteriza, representadas en acciones de impacto humanitario ${ }^{6}$ como las registradas por el omc (figura 1).

En primera instancia se evidencia que, hasta la década de los ochenta, con la llegada

FIGURA 1. PERIODIZACIÓN ANUAL DE ACCIONES DEL ELN

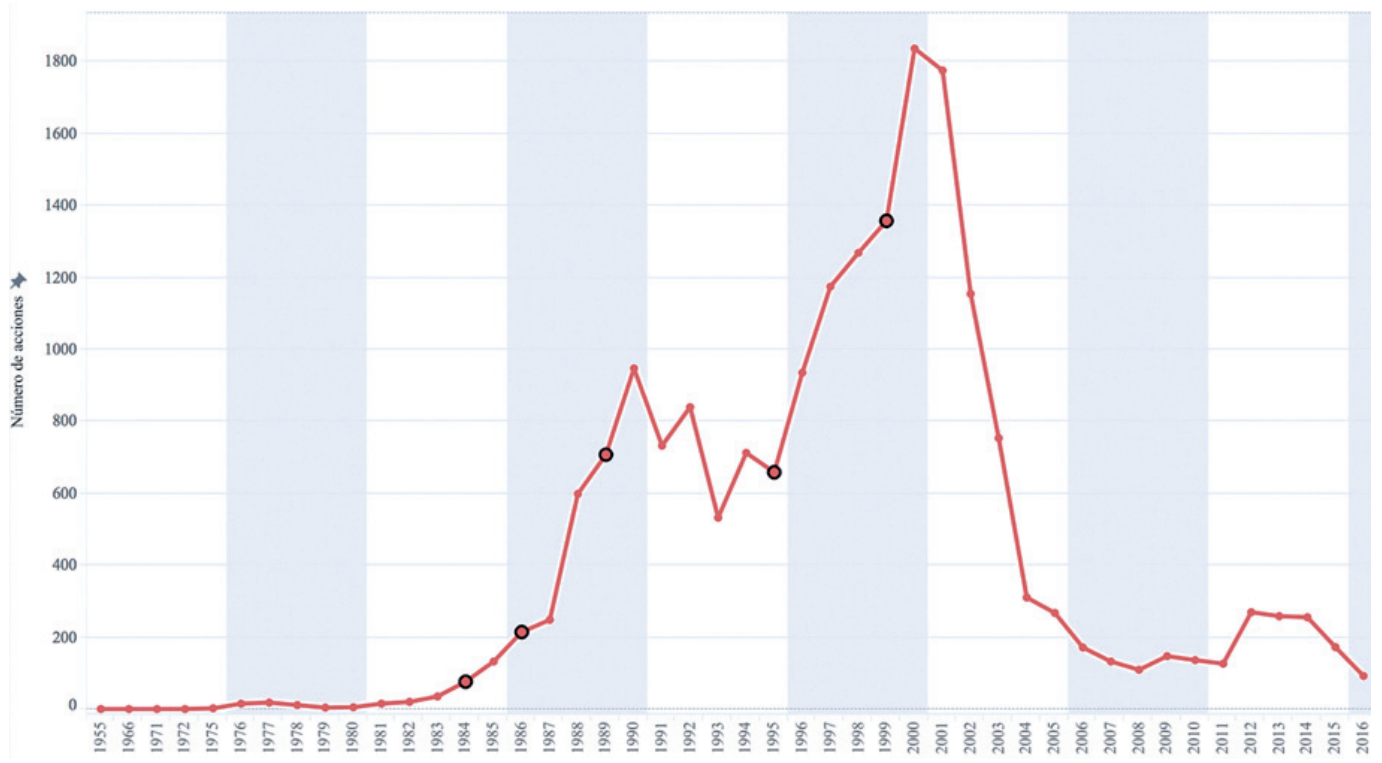

Fuente: $\mathrm{CNMH}$, Bases de datos, Observatorio de Memoria y Conflicto (fecha de corte: 15/05/2017). Visualización de datos: Claudia Báez.

5 A principios de 2000, el eLN contaba con 4.700 integrantes distribuidos en siete frentes de guerra; actualmente reúne 1.330 guerrilleros (Echandía, 2013).

6 La sumatoria total tiene en cuenta casos de secuestro, daño a bienes civiles, asesinatos, desapariciones y acciones bélicas. 
de la Mannessmann (año señalado con el primer punto en la línea de la figura 1), el ELN adquiere la capacidad financiera de aumentar el número de acciones y consolidarse como actor armado del conflicto colombiano. El grupo se enfrentaba en aquel momento a dificultades económicas, y a pugnas y fusilamientos en su interior que amenazaban con desaparecerlo, pero gracias a las rentas de la extorsión a empresas petroleras, y al millonario pago del rescate de los ingenieros europeos secuestrados, el ELN logró recaudar cerca de 3.000 millones de pesos, lo que lo convirtió en uno de los grupos con mayor ingreso per cápita del planeta (Semana, 1999). Dichos ingresos le permitirían, en el marco de la mencionada campańa "Vida y soberanía Manuel Gustavo Chacón", ampliar sus acciones contra la infraestructura petrolera y aumentar su iniciativa bélica en la confrontación (figura 2).

De hecho, al revisar los tipos de acciones de la década (figura 2) se entiende que, a partir de 1985, la ascendente participación del eLN se limita a acciones bélicas y daños a bienes civiles, justificados en la voladura de oleoductos y otros atentados a la industria extractiva. Adicionalmente, se evidencia un escalamiento hacia el año 1988, cuando el Gobierno presentó su Iniciativa para la Paz; el eLN no se interesó en los diálogos de paz y, en cambio, decidió atacar los pilares de la economía nacional (industria petrolera). Así, la dinámica de las acciones ejecutadas por esta guerrilla durante los años ochenta respondió a la estrategia que muchos dieron en llamar "petroterrorismo": "lo que en un principio se presentó como su bandera en

FIGURA 2. PERIODIZACIÓN ANUAL DE ACCIONES DEL ELN DESAGREGADO POR TIPO DE ACCIÓN 1980-1990

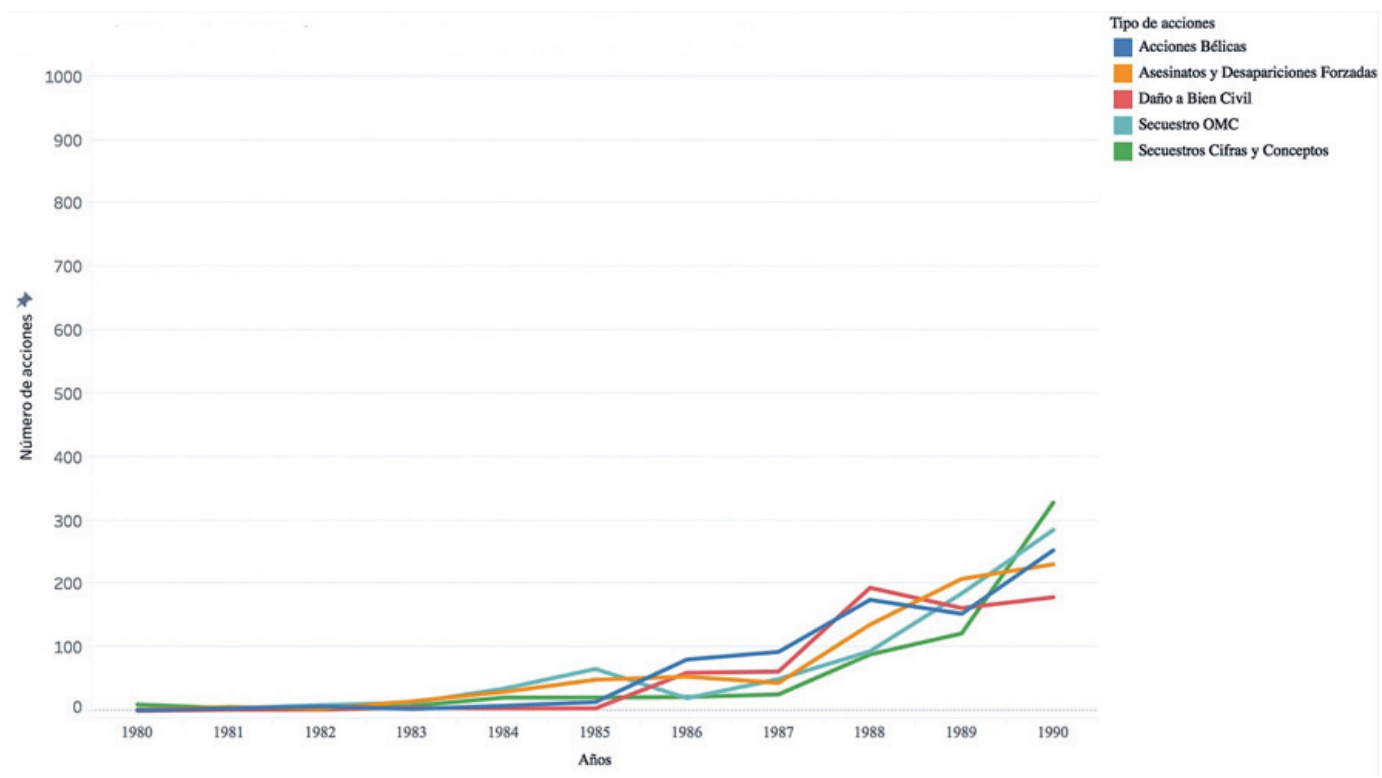

Fuente: CNMH, Bases de datos, Observatorio de Memoria y Conflicto (fecha de corte: 15/05/2017). Visualización de datos: Claudia Báez. 
defensa de la soberanía nacional y los recursos no renovables, se fue transformando en su más poderosa arma en la confrontación y principal fuente de financiamiento" (Echandía, 2015).

Por su parte, la década de los noventa inicia con un repunte de las acciones bélicas y de los daños a bienes civiles (1992), justificado por el fracaso de los diálogos de paz con la administración Gaviria y la consecuente agudización del conflicto (Echandía, 2015). Sin embargo, la dinámica más significativa de la década corresponde a los secuestros, cuyo ascenso a partir de 1996, con un pico en 1999, responde directamente al plagio de Brigitte Schönne (1996), el avión de Avianca y la congregación de La María (1999). No sobra recordar que, en el marco de la estrategia de internacionalización hacia Europa, el ELN justificó esta ola de secuestros como un medio de presión al gobierno Pastrana para entablar negociaciones de paz (figura 3 ).

$\mathrm{Al}$ revisar el total agregado de acciones de la década (figura 1), y teniendo en cuenta lo anterior, se entiende que 1996 es un ańo clave para el ELN, pues el millonario pago del rescate de Schönne, recibido gracias a la mediación de los Maüss, le otorga al grupo guerrillero los recursos suficientes para escalar sus acciones de guerra y confrontaciones bélicas hasta el punto más alto de su historia en 1999. Así, el periodo 1996-1999 constituye el de mayor impacto del ELN en el conflicto; no obstante, del 2000 en adelante, la dinámica es justamente la opuesta (figura 4).

\section{FIGURA 3. PERIODIZACIÓN ANUAL DE ACCIONES DEL ELN DESAGREGADO POR TIPO DE ACCIÓN 1999-2000}

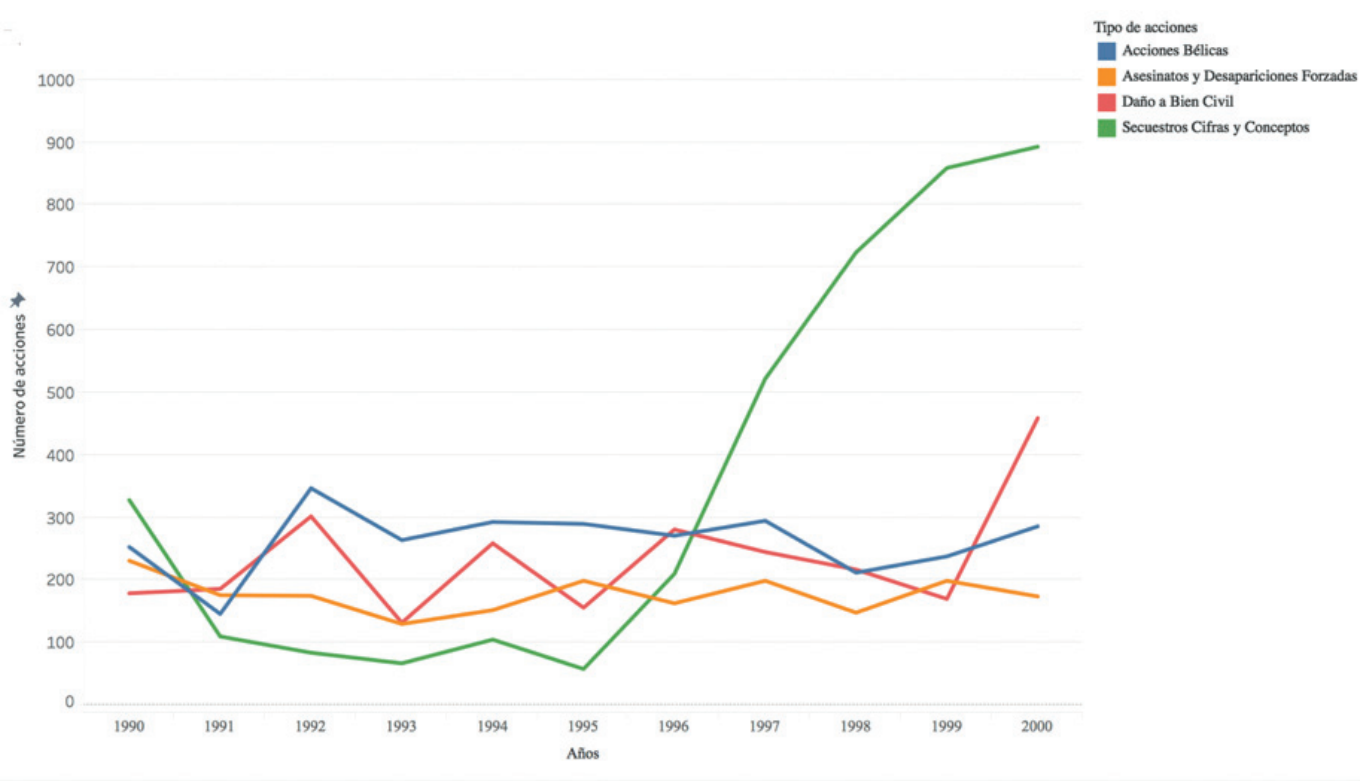

Fuente: CNMH, Bases de datos, Observatorio de Memoria y Conflicto (fecha de corte: 15/05/2017). Visualización de datos: Claudia Báez. 
FIGURA 4. PERIODIZACIÓN ANUAL DE ACCIONES DEL ELN DESAGREGADO POR TIPO DE ACCIÓN 2000-2016

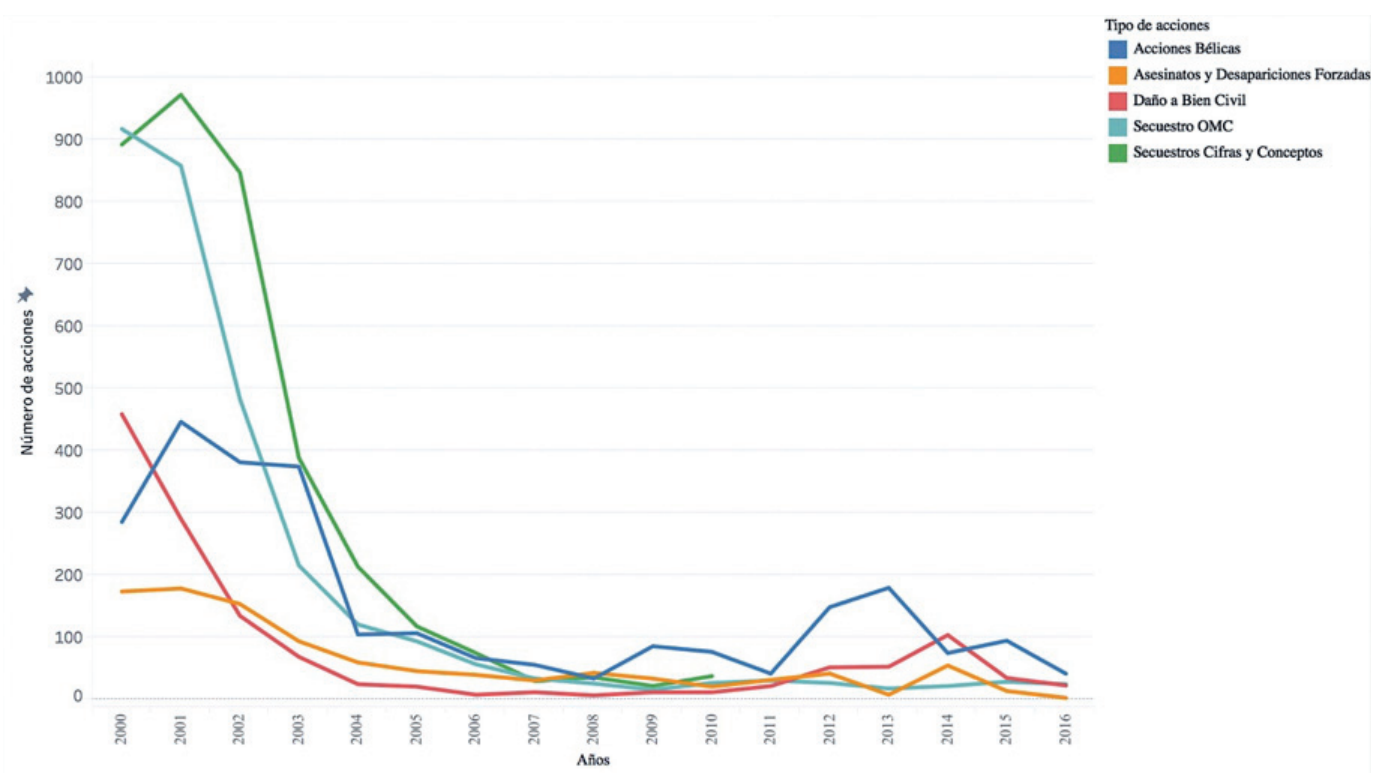

Fuente: CNMH, Bases de datos, Observatorio de Memoria y Conflicto (fecha de corte: 15/05/2017). Visualización de datos: Claudia Báez.

Durante el gobierno Uribe las Fuerzas Militares aumentaron significativamente el número de combates lo que, sumado a la confrontación con las Autodefensas Unidas de Colombia (AUC), y al protagonismo armado que adquirieron las FARC, con quienes el ELN también tuvo disputas locales (que traspasaron la frontera venezolana), condujo a la reducción de la capacidad bélica de esta guerrilla. De hecho, a partir de 2006 el ELN se ve obligado a replegarse y a minimizar los sabotajes contra el oleoducto, dada la paulatina pérdida de poder militar y político. Dicha situación se mantiene hasta 2011 (figura 1) cuando las acciones ascienden, buscando presionar hacia la actual negociación de paz; este es, también, el motivo por el cual las acciones descienden nuevamen- te a partir de 2013, ańo en el que el gobierno Santos anuncia el inicio de los contactos con el ELN para definir una agenda de negociación (Echandía, 2015) (figura 5).

En general, la periodización de las acciones del ELN evidencia que su estrategia de internacionalización impactó su dinámica de acción. Como se expuso, la llegada de la Mannessmann a Colombia (1984) es el punto de inflexión, especialmente en términos financieros, para la consolidación del ELN como actor del conflicto; asimismo, los ascensos y descensos de la década de los noventa están relacionados con la mesa de negociación y, por tanto, con la estrategia de internacionalización hacia Europa. 


\section{FIGURA 5. PERIODIZACIÓN ANUAL DE ACCIONES DEL ELN}

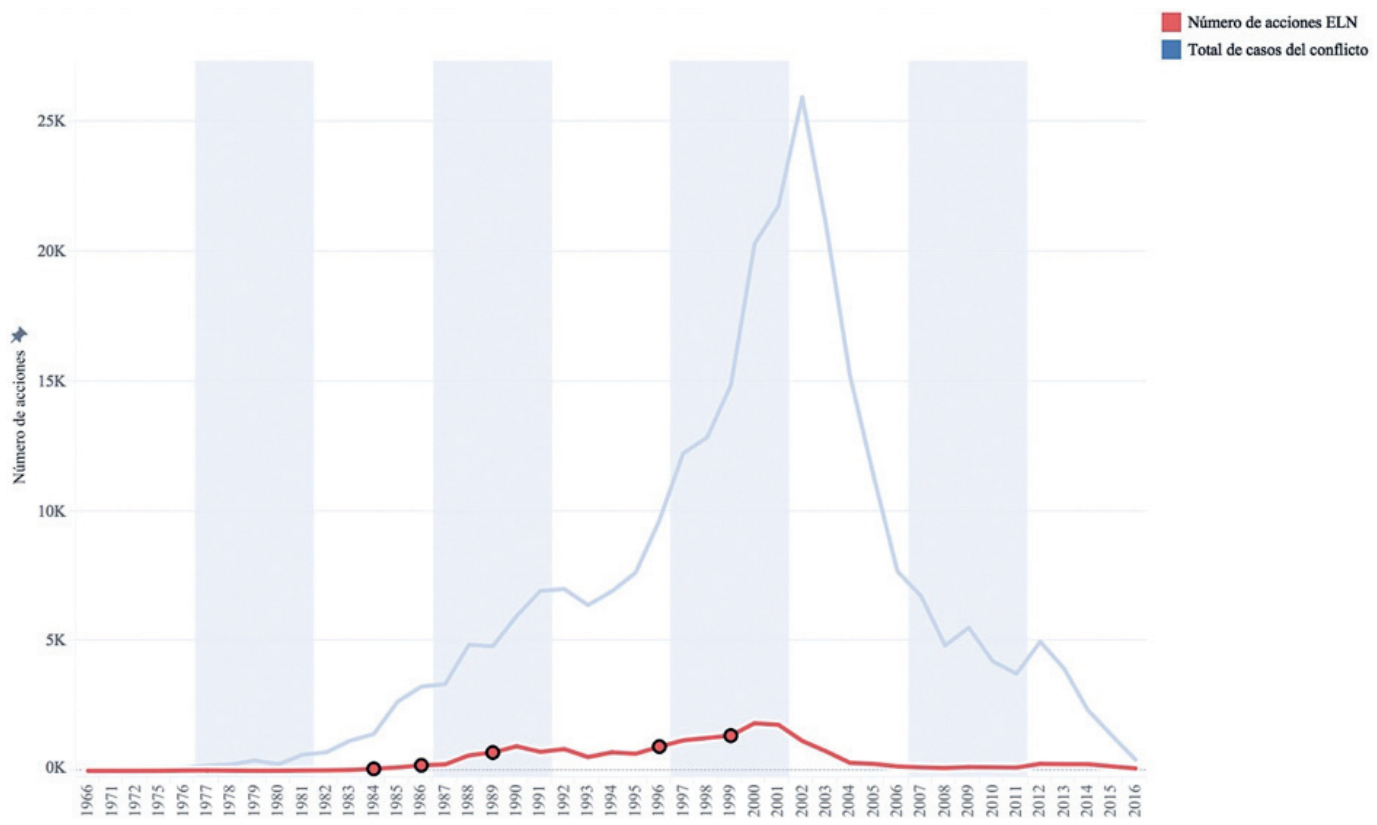

Fuente: CNMH, Bases de datos, Observatorio de Memoria y Conflicto (fecha de corte: 15/05/2017). Visualización de datos: Claudia Báez.

De la misma manera, el periodo de mayor crecimiento y fuerza bélica de esta guerrilla (1996-1999) dependió directamente de los recursos recibidos por el pago del rescate de Schönne; ello coincide con que en este mismo periodo, con la ayuda de sus contactos con los Maüss y altos mandatarios alemanes, delegaciones guerrilleras viajaran en varias ocasiones a Europa. En los años más recientes, los repuntes y las disminuciones en las acciones del ELN han respondido, nuevamente, a los diferentes momentos de la negociación.

Al revisar la figura 5 se evidencia que el ELN no ha tenido un rol significativo sobre el total de acciones del conflicto colombiano; igualmente, es posible entender que el repunte que ha tenido en ańos recientes no es compa- rable al nivel de acciones que tuvieron, por ejemplo, en la década de los ochenta o noventa. Sin embargo, revisar de manera específica las acciones bélicas (figura 6) permite evidenciar que en las décadas de los ochenta y de los noventa lograron mantener una superioridad en el número de acciones de confrontación contra las fuerzas armadas estatales.

Sin embargo, a partir del Gobierno Pastrana el ELN se ve obligado a replegarse por el accionar paramilitar y de las fuerzas estatales, lo que redujo el número de acciones bélicas iniciadas hasta niveles comparables a los de sus dos primeras décadas de existencia; a partir de este momento, quien mantiene el protagonismo armado es la guerrilla de las FARC. Asimismo, la figura 6 evidencia que, si bien los 


\section{FIGURA 6. ACCIONES BÉLICAS SEGÚN INICIATIVA}

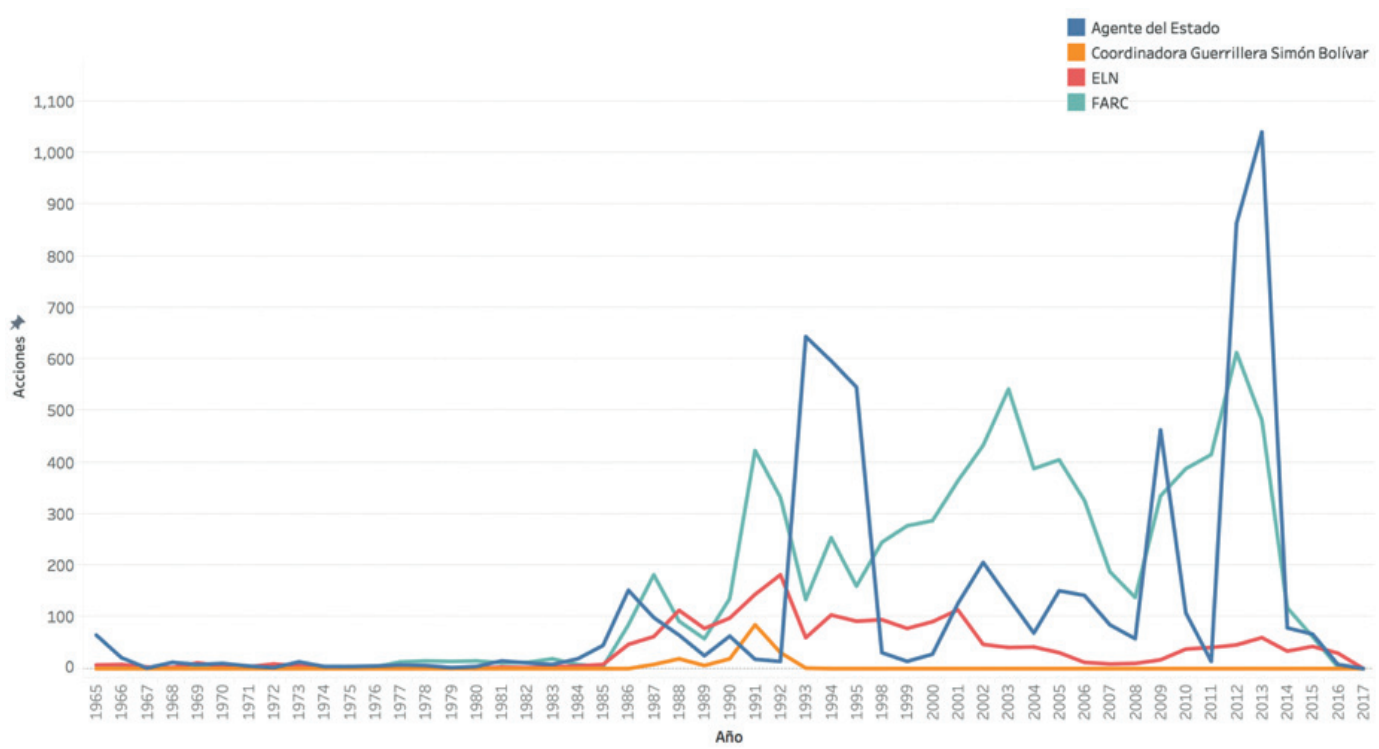

Fuente: CNMH, Bases de datos, Observatorio de Memoria y Conflicto (fecha de corte: 15/05/2017). Visualización de datos: Claudia Báez.

últimos años han presentado un repunte en la confrontación, este no llega a ser comparable al nivel de acciones de confrontación iniciadas en la década de los noventa. En general, se mantiene integrado a la dinámica del conflicto, con un grado de protagonismo armado hasta finales de los noventa, cuando se empieza a diluir su impacto en la dinámica, sin lograr todavía recuperarse.

\section{Correlación de fuerzas y negociación}

Para Walter (1997), una de las variables más importantes para que los actores de un conflicto decidan negociar es la evaluación del "costo de alcanzar la victoria”, que contempla la duración, magnitud ${ }^{7}$ e intensidad ${ }^{8}$ de la guerra, y la presencia de un estancamiento militar. Adicionalmente, otros académicos afirman que el resultado y la duración de las guerras civiles depende del balance militar entre el Estado y los otros actores armados, y de los incentivos existentes para llegar a un acuerdo; así, se optará por una salida negociada solo cuando haya paridad de poder (Cunningham et al., 2009). Con lo anterior en mente se puede revisar el caso colombiano. De un lado, más de cincuenta años han pasado desde el surgimiento del ELN, lo que implica que el escenario nacional e internacional ha cambiado;

\footnotetext{
$7 \quad$ Número de muertos por cada 1.000 personas.

$8 \quad$ Número de muertes por mes.
} 
los aliados que esta guerrilla tiene, o a los que podría acceder ahora, por cuenta de su origen en la Revolución Cubana y de su ideología de izquierda son bastante reducidos. De hecho, la relación del ELN con Alemania parece haber culminado con la salida de Kohl en 1998 y, no es claro que el ELN siga recibiendo el apoyo clandestino de países europeos.

De otro lado, aun cuando en los años más recientes el ELN ha aumentado sus acciones bélicas y ha aprovechado el vacío de las FARC para expandir su presencia territorial, tales acciones se caracterizan por requerir del factor sorpresa para compensar la inferioridad militar, así que "la estructura ya no cuenta con capacidad ofensiva que involucre Alto esfuerzo militar, e incluso los frentes se muestran replegados y no registran actividad en muchos escenarios con presencia previa” (Echandía, 2015).

Adicionalmente, la seguridad fronteriza se ha visto afectada por el fortalecimiento de la presencia del ELN en la zona, obtenido a través de la competencia armada por el control del narcotráfico, lo que ha implicado una significativa afectación a la población civil, pues el grupo ha asesinado a pobladores y miembros de organizaciones sociales que perciben como apoyo de sus enemigos (Lozano, 2016).

Además de los asesinatos, la mencionada competencia armada degeneró en un aumento de los casos de desplazamiento forzado y de víctimas de minas antipersonal, por cuenta de su siembra en lugares utilizados como corredores del narcotráfico. Esta creciente relación del ELN con el narcotráfico cobra todavía más relevancia si se tiene en cuenta que esta guerrilla, al ser federalista, enfrenta la posibilidad de que, en caso de llegar a un acuerdo de paz con el Gobierno, una parte significativa de sus combatientes no acceda a desmovilizarse ${ }^{9}$ (Echandía, 2015).

En pocas palabras, el grupo ha fortalecido su presencia territorial bajo el costo de la degradación del conflicto y, dado su creciente involucramiento con el narcotráfico, de poner en tela de juicio su ideología revolucionaria, comprometiendo así su base social, fundamental para que la lucha revolucionaria se revista de legitimidad. De esta manera, en términos de la correlación de fuerzas, todo apunta a que el ELN no llegó a la mesa de negociación con una posición fuerte ni a nivel nacional ni internacional.

Adicionalmente, el ELN insiste en imponer una negociación sin condiciones. Más allá de la imprecisión en la agenda propuesta ${ }^{10}$, el modelo de cese al fuego sin concentración espacial de los frentes guerrilleros probó ser inefectivo con hechos como el asesinato del gobernador indígena del Chocó (24 de octubre de 2017), evento al que siguió la renuncia del jefe negociador (04 de diciembre de 2017).

9 El ELN incrementa su acción militar en el Chocó, por lo que el jefe negociador afirmó que "el grupo subversivo del ELN en este departamento es bastante suelto, díscolo, y no parece leer con claridad ni seguir las instrucciones de los comandos centrales que están sentado en la mesa”. Por ello, pidió que un representante de estas unidades guerrilleras se trasladara cuanto antes a la mesa de diálogos, como muestra de unidad de criterio frente al proceso de paz (El Espectador, 2017).

10 Solo definir la participación de la sociedad en la negociación, y ponerla en práctica, podría tomar años. 
Veinte días después el ELN se retiró, a través de su cuenta de Twitter, del Mecanismo de Veeduría y Verificación del cese temporal pactado con el Gobierno, argumentando incumplimiento de lo acordado, hostilidades a guerrilleros y que el mecanismo había colapsado. Posteriormente, al finalizar el cese al fuego pactado, el ELN reactivó sus ataques contra la infraestructura petrolera y las Fuerzas Armadas ${ }^{11}$, por lo que el presidente Santos tomó la decisión de suspender las negociaciones ${ }^{12}$ (Portafolio, 2018).

Lo analizado permite afirmar que una ampliación de los tiempos de negociación, así como la implementación de un cese al fuego bilateral, sirve perfectamente a los intereses de ampliación y fortalecimiento de la presencia territorial del ELN en aquellos espacios que las FARC dejan con su salida del conflicto. Por supuesto, el discurso del ELN niega esta realidad. En su página de internet han publicado comunicados respecto al actual escenario y afirman, entre otras cosas, que la crisis de la negociación inició porque el gobierno no asistió a la mesa de negociación el 10 de enero (ELNPAZ, 2018).

De otro lado, hay quienes consideran que la fuerza del ELN no reside en su capacidad militar sino en su base social y política, sobre la cual se habrían volcado en la última década (Vargas, 2014); y que, a pesar del debilitamiento territorial y orgánico que ha sufrido, se mantiene como una fuerza organizada, con capacidad de injerencia en las dinámicas sociales, políticas y económicas de los territorios en los que tiene presencia; en consecuencia, aunque no tiene la capacidad de amenazar la estabilidad del Estado, logra mantenerse como un elemento de perturbación (Celis, 2015).

No obstante, los actores del conflicto deben evaluarse con base en sus hechos y no en su discurso. Así, lo mencionado por Vargas queda en tela de juicio al revisar procesos como el del sur de Bolívar, analizado previamente en esta investigación; en este punto, argumentar que la base social es clandestina no es suficiente para ganar peso en la mesa de negociación. Igualmente, la postura de Celis se controvierte cuando el exjefe negociador del Gobierno vio la necesidad de solicitar la presencia en la mesa de un representante de la estructura del ELN en Chocó.

Entonces, la viabilidad del proceso de negociación entre el Gobierno y el ELN depende de que el grupo guerrillero haga una correcta lectura de la correlación política y militar de fuerzas, como condición indispensable para la construcción de consensos en torno al propósito común de ponerle fin al conflicto armado (Cabrera y Echandía, 2017). Dicha organización no puede pasar por alto, además, que su historia, en cuanto a diálogos y negociaciones de paz, ha hecho mella en la población civil, lo que ha generado desconfianza en sus iniciativas de paz, tanto a nivel nacional como internacional.

11 El ELn ejecutó tres ataques en Barranquilla y otras poblaciones del norte de Colombia, con un saldo de 7 policías muertos y 47 heridos (Portafolio, 2018).

12 El presidente Santos afirmó que "el ELN ya no tiene capacidad de dar golpes militares, solo puede hacer actos de terrorismo que afectan a la población civil y al medio ambiente, que dicen defender” (El Tiempo.com, 2018). 


\section{CONCLUSIONES}

Es posible concluir, en primera instancia, que el conflicto colombiano se vio sujeto a un proceso de internacionalización que, en una de sus facetas, fue efectivamente iniciado por el ELN, como parte de una clara y calculada estrategia. Dicha estrategia tuvo, desde muy tempranos momentos, una importancia significativa dentro del grupo subversivo, lo que se encuentra justificado en el enraizamiento de su origen en la Revolución Cubana y, por tanto, en la lucha global de la izquierda socialista.

Aun cuando esta estrategia tuvo un alcance bastante amplio, pues no solo logró generar alianzas en Latinoamérica, sino que también alcanzó a tocar las puertas de los Estados europeos, fue poco exitosa en términos de internacionalización politica pues, así como no llegaron a conformar una base social fuerte que los apoyara al interior, no lograron conseguir un apoyo continuo que se tradujera en legitimidad desde los actores internacionales. Esta falta de legitimidad, tanto nacional como internacional, debería ser un factor para tener en cuenta por el grupo subversivo ahora que se sienta a la mesa de negociación con el Gobierno. Igualmente, la periodización de las acciones llevadas a cabo por el ELN durante el conflicto colombiano permite evidenciar que, ciertamente, la estrategia de internacionalización fue determinante en su accionar armado, pero no logró alterar la dinámica general del conflicto de manera significativa.

Lo anterior tiene implicaciones importantes para las actuales negociaciones de paz entre el ELN y el Gobierno, dada la incertidumbre que genera la falta de cohesión de la organización y lo que ello implica para el cumplimento del cese al fuego bilateral. A ello se suma la desconfianza acumulada por una larga historia de intentos fallidos de negociación con esta guerrilla, y lo que parece ser una falta de coherencia entre las condiciones en las que el ELN quiere llevar la mesa de diálogo, frente a su capacidad real de exigirlas, teniendo en cuenta su bajo poderío militar y la erosión del respaldo social. Mientras tanto, es claro que el proceso y la condición de regionalización del ELN como parte de su esfuerzo de supervivencia seguirá teniendo un impacto directo en la seguridad de las zonas de frontera donde aún tiene presencia esta guerrilla.

Aun cuando no puede hablarse con certeza de la existencia de una estrategia de internacionalización implementada en la actual mesa de negociación por parte del ELN, es evidente que el crecimiento del grupo en el actual escenario pos-FARC, especialmente en las zonas de frontera, seguirá generando dificultades para que el Gobierno, quien debe acogerse al derecho internacional y respetar la soberanía de los Estados vecinos, finalice el conflicto por medio de la confrontación militar. Más bien, las condiciones están dadas para que, a menos que se obtenga la paz por vía negociada, el conflicto se prolongue de manera indefinida, debido a las crecientes rentas del narcotráfico a las que podría tener acceso el ELN. Sin embargo, esta guerrilla debe sopesar lo que un mayor acceso a dichas rentas implicaría en términos políticos $y$, por tanto, en lo que respecta a su legitimidad a nivel interno y externo. 


\section{REFERENCIAS}

Aguilera, M. (2006). eln: entre las armas y la política. En F. Gutiérrez, Nuestra Guerra Sin Nombre: transformaciones del conflicto en Colombia (pp. 209-266). Bogotá D.C.: Editorial Norma.

AH-ELn (2012). III Congreso. Periodo. La dirección de los vientos. En C. Medina, Ejército de Liberación Nacional, notas para una historia de las ideas politicas (pp. 630-631). Bogotá D.C.: Universidad Nacional de Colombia.

AH-ELN (2012). Simacota 12. Estrategia revolucionaria. Conceptualización. En C. Medina, Ejército de Liberación Nacional, notas para una historia de las ideas políticas. Bogotá D.C.: Universidad Nacional de Colombia.

Alarcón Ramírez, D. (1997). Memorias de un soldado cubano: vida y muerte de la Revolución. Barcelona: Tusquets.

Allison, G. (1971). Essence of Decision: Explaining the Cuban Missile Crisis. Boston: Little Brown.

Álvarez et al. (2017). Crimen organizado y saboteadores armados en tiempos de transicion. Bogotá D.C.: Informes FIP No. 27.

Aponte, D. y Vargas, A. (2011). No estamos condenados a la guerra. Hacia una estrategia de cierre del conficto con el ELN. Bogotá: ODECOFI y Colciencias. Ávila, L. y Ávila, J. (9 de noviembre de 2016). GobiernoELN: 30 años de diálogos y fracasos. Con Lupa. Bogotá: Universidad del Rosario.

ввс Mundo (5 de octubre de 2017). Quién es Werner Maüss, el superespía condenado por la justicia de Alemania que medió entre la guerrilla del ELN y el gobierno de Colombia en 1995. ввс Mundo.

Borda, S. (2012). Internacionalización de la paz y de la guerra en Colombia durante los gobiernos de Andrés Pastrana y Álvaro Uribe. Bogotá: Universidad de los Andes.
Cabrera, I. (2012). Conflictos armados en zonas de frontera: análisis a partir del caso colombiano. En J. Aguilar, ¿Prolongación sin solución?: perspectivas sobre la guerra y la paz en Colombia (pp. 77-122). Bogotá: Universidad Externado de Colombia.

Cabrera, I. y Echandía, C. (2017). Madurez para la paz: evolución de la territorialidad y las estrategias en el conflicto armado colombiano. Bogotá: Universidad Externado de Colombia.

Celis, L. E. (2015). Tres argumentos para negociar con el eln. En V. De Currea-Lugo (ed.), ¿Por qué negociar con el ELN? (pp. 25-29). Bogotá D.C.

Celis, L. E. (14 de septiembre de 2017). Estrategia de Internacionalización del ELN. (M. C. Beltrán, entrevistadora), Bogotá.

Clausewitz, K. V. (1942). De la Guerra. Bogotá: Estado Mayor General de las Fuerzas Militares.

Corporación Nuevo Arcoiris (2013). Informe general del estado del conflicto armado en Colombia. Del Caguán a La Habana. Bogotá D.C.: Observatorio del Conflicto Armado.

Cunningham et al. (2009). It takes two: a dyadic analysis of civil war duration and outcome. The Journal of Conflict Resolution, 53 (4), 570-597.

Currea-Lugo, V. (2015). De los fines y las formas. En V. De currea-Lugo (ed.), Negociación GobiernoELN. Y sin embargo, se mueve (pp. 17-22). Bogotá D.C.: Ántropos Ltda.

Currea-Lugo, V. (14 de septiembre de 2017). Estrategia de internacionalización del eLN (M. C. Luna, entrevistadora), Bogotá.

Currea-Lugo, V. (24 de julio de 2017). ¡Nos vamos de tregua! La Silla Vacía.

Echandía, C. (2013). Auge y declive de Ejército de Liberación Nacional (ELN). Bogotá D.C.: Fundación Ideas para la Paz.

Echandía, C. (2015). El ABC del ELN. Evolución del Frente de Guerra Oriental (territorialidad, iniciativa armada y relación con la población y las economias ilegales). Bogotá: Fundación Ideas para la Paz. 
El Espectador (7 de julio de 2014). El Frente Domingo Laín, mitos y realidades de una máquina de guerra. El Espectador.

El Espectador (9 de mayo de 2017). Gobierno pide al ELN llevar a la mesa de diálogos representante de sus estructuras en Chocó. El Espectador.

ELN (17 de agosto de 2017). Mitos y leyendas del ELN (tercera parte). Recuperado de http://eln-voces. com/index.php/voces-del-eln/militancia/1196mitos-y-leyendas-sobre-el-eln-tercera-parte

ELNPAZ (12 de febrero de 2018). Delegación de Diálogos. Recuperado de http://eln-paz.org/index.php/ sociedad/32-equipo-comunicaciones/153-lineade-tiempo-de-la-fase-publica-de-negociaciones

Eltiempo.com (11 de febrero de 2018). Santos dice que con el ELN "va a ser difícil retomar diálogos". El Tiempo.

Fundación Ideas para la Paz (17 de junio de 2005). La derrota de la coca. Siguiendo el conflicto: hechos $y$ análisis de la semana, 17.

Fundación Paz y Reconciliación (2017). Cómo va la paz. Segundo informe de la iniciativa Unión por la Paz. Bogotá D.C.: Fundación Paz y Reconciliación. Gleditsch, K. (2007). Transnational Dimensions of Civil War. Journal of Peace Research, 44 (3), 293-309.

Gómez, I. (1998). La última misión de Werner Maüss. Colección Primera Plana. Bogotá: Editorial Planeta.

González, C. (2015). La primera negociación en la historia del ELN. En V. De Currea-Lugo (ed.), Negociaciones Gobierno-ELN. $Y$ sin embargo, se mueve (pp. 43-51). Bogotá D.C.: Ántropos Ltda.

Gutiérrez, O. (2004). La oposición regional a las negociaciones con el eln. Análisis Politico (52), 34-50.

Henao G., H. F. (2014). La Iglesia católica colombiana y el trabajo por la paz. En V. Bouvier (ed.), Colombia: la construcción de la paz en tiempos de guerra (pp. 173-190). Bogotá D.C.: Universidad del Rosario.
Hill, S. y Rothchild, D. (abril de 1986). The Contagion of Political Conflict in Africa and the World. Journal of Conflict Resolution (30).

Hoffman, M. y Forbes, I. (1993). Political Theory, International Relations and the Ethics of Intervention. London: MacMillan.

International Crisis Group (2007). ¿Se está avanzando con el ELN? Boletín informativo sobre América Latina.

La W (09 de septiembre de 2017). W Radio. Obtenido de http:/www.wradio.com.co/noticias/ actualidad/masacre-de-tumaco-fue-una-violacion-al-cese-el-fuego-bilateral-eln/20171009/ nota/3603113.aspx

Lozano, C. (02 de septiembre de 2016). Carta a Gabino. Semanario Voz.

Medina Gallego, C. (2010). FARC-EP y ELN: una historia politica comparada (1958-2006). Bogotá: Universidad Nacional de Colombia.

Medina Gallego, C. (2012). Ejército de Liberación Nacional. Notas para una historia de las ideas politicas. Bogotá D.C.: Universidad Nacional de Colombia.

Medina Gallego, C. (2015). El poder popular en la vida del ELN. El camino hacia su lucha social y política. En V. De currea-Lugo (ed.), Negociación Gobierno-ELN. Y sin embargo, se mueve (pp. 159169). Bogotá D.C.: Ántropos Ltda.

Movimiento de Presos Políticos "Camilo Torres Restrepo" (2016). El ELN y la paz en Colombia, línea de tiempo. En V. De Currea-Lugo (ed.), Metiéndole pueblo a la paz (pp. 287-305). Bogotá D.C.: Ántropos Ltda.

Núñez, M. (2010). ELN: debilitamiento nacional y fortalecimiento regional. En Corporación Nuevo Arcoiris, Balance de las FARC. Después de Jojoy y los nuevos carteles del narcotráfico (pp. 62-72). Bogotá D.C.: Observatorio del Conflicto Armado. 
Observatorio de Memoria y Conflicto (15 de mayo de 2017). Bases de Datos. Centro Nacional de Memoria Histórica.

olas (1967). Primera Conferencia de la Organización Latinoamericana de Solidaridad . Recuperado de http://www.ruinasdigitales.com/revistas/ ConferenciaTricontinental.pdf

Olaya, C. y León, S. (2013). ¿Qué tanta fuerza tiene el ELN para negociar? Informe general del estado del conflicto armado en colombia, del Caguán a La Habana. Bogotá D.C.: Observatorio del Conflicto Armado.

Palacios, M. et al. (1999). Los laberintos de la guerra: utopias e incertidumbres sobre la paz. Bogotá D.C.: Tercer Mundo y Universidad de los Andes. Palacios, M. (2012). Violencia Pública en Colombia, 1958-2010. Bogotá D.C.: Fondo de Cultura Económica.

Pizarro, E. (1991). Elementos para una sociología de la guerrilla en Colombia. Análisis Politico, 12.

Portafolio (29 de enero de 2018). Gobierno suspende negociación de paz con el eln. Portafolio.

Ramírez, S. (2006). La ambigua regionalización del conflicto colombiano. En Universidad NacionalIEPRI, Nuestra guerra sin nombre: transformaciones del conflicto en Colombia (pp. 123-167). Bogotá: Grupo Editorial Norma.

Schlenker, J. e Iturralde, M. (2006). El uso del discurso de los derechos humanos por parte de los actores armados en Colombia: ¿humanización del conflicto o estrategia de guerra? Análisis Politico, 56, 29-50.

Semana (11 de septiembre de 1998). Relaciones peligrosas. Revista Semana, 858.

Semana (12 de julio de 1999). El elN y los alemanes. Revista Semana, 893.

Semana (27 de noviembre de 2000). La guerra diplomática. Revista Semana, 965. Recuperado de http://www.semana.com/nacion/articulo/laguerra-diplomatica/44175-3

Ugarriza, J. y Pabón, N. (2017). Militares y guerrillas. La memoria histórica del conflicto armado en Colombia desde los archivos militares 1958-2016. Bogotá D.C. Editorial Universidad del Rosario.

Valencia, L. (2014). El vacilante avance del eLN hacia la paz. En V. Bouvier (ed.), Colombia: la construcción de la paz en tiempos de guerra (pp. 135-152). Bogotá D.C.: Universidad del Rosario.

Vargas, A. (1998). Tres momentos de la violencia política en San Vicente de Chucurí: de los bolcheviques del año 29 a la fundación del eln. Análisis Politico, 8, 28-45.

Vargas, A. (2014). ¿¿Por qué se debe negociar con el ELn? En V. De Currea-Lugo (ed.), ¿Por qué negociar con el ELN? (pp. 43-50). Bogotá D.C.: Pontificia Universidad Javeriana.

Vargas, A. (9 de noviembre de 2016). Gobierno-ELN: 30 años de diálogos y fracasos (J. Ávila y C. Ávila, entrevistadoras). Bogotá: Universidad del Rosario.

Velandia, C. (2014). La paz: ahora o nunca. En V. De Currea-Lugo (ed.), ¿Por qué negociar con el ELN? (pp. 43-50). Bogotá D.C.: Pontificia Universidad Javeriana.

Vergara, H. (07 de septiembre de 2017). Estrategia de internacionalización del ELN (M. C. Beltrán, entrevistadora), Bogotá.

Walter, B. (marzo de 1997). The critical barrier to civil war settlement. International Organization (51), 335-364.

Zuluaga, J. (2013). Negociar con el ELN: ¡imperativo de paz! Revista Zero (30).

Zuluaga, J. (10 de agosto de 2017). Dimensión internacional del ELN. (M. C. Luna, entrevistadora), Bogotá. 